\title{
CASELOAD COMPLEXITY DEMYSTIFIED
}

The complex needs of the patients

treated by community and special care

dentists can be lost on health officials and

commissioners, according to Charlotte

Waite, Chair of the BDA's England

Community Dental Services Committee.

She was commenting on the updated

Case Mix tool, a software-based scoring

system to help clinicians identify the

particular issues vulnerable patients

encounter in accessing dental treatment.

Speaking at the launch of the revised tool,

she said: 'Since its inception, BDA case

mix has demonstrated to commissioners

the challenges and value of the work

community and special care dentists do.

This new version will take this approach to the next level.'

Following input from the British Society of Disability and Oral Health and the British Society of Paediatric Dentistry, the tool has been extended while definitions

already included for adult patients have also been revised.

The tool was first launched in 2008 to help dentists score the complexity of adult patients requiring special care dentistry and has become the gold standard for such scoring, according to six identifiable criteria. These are:

- ability to co-operate

- ability to communicate

- medical status

- oral risk factors

- access to oral care

- legal and ethical barriers to care

Results are used in commissioning and contract matters as well as in wider epidemiological work. Although CDS dentists are its prime users, the tool can be used by general dental practitioners or secondary care providers. Most dental software providers already provide case mix scoring in their programes and work is underway to upgrade these.

Dr Waite added: 'The NHS Long Term Plan pledges links to learning disability and autism services, and a holistic approach to care. It's an approach we take on a daily basis, empowered by BDA case mix, and now children can benefit fully with a system designed around their unique needs.' Case Mix 2019 is available at https://www.bda.org/casemix.

\section{Health \\ claims on \\ children's food 'confusing', say researchers}

Researchers from the University of Glasgow have called for tighter regulations on food labelling. They say health and nutrition claims on snacks and food for UK children are 'confusing' and could be harming their health.

Two in five products marketed at those over the age of one, including cereals and fruit-based drinks, were found to be 'less healthy,' according to analysis published in the journal Archives of Disease in Childhood.

Meanwhile, three-quarters of products which claimed to contain one of the five recommended daily portions of fruit and vegetables did not, the research team found, warning that a false impression of some foods, for example those high in sugar, is being created.

\section{ADVANCING DENTAL CARE PROGRAMME ADVANCES}

A prevention oriented NHS has been promised by Health Education England (HEE) which has announced that Malcolm Smith is the new Chair of their Advancing Dental Care (ADC) programme.

A former Postgraduate Dental Dean for HEE North East, Malcolm, has a wealth of experience in dental education commissioning and training. His role will be to develop the dental workforce over the second phase of the ADC programme from 2019-2021, ensuring close alignment with the priorities outlined in the Long Term Plan for the NHS.

Leading on a broad programme which is designed to deliver the recommendations of the 2017-18 Advancing Dental Care Review, Malcolm will take an evidence-based approach to develop dental training that responds to the changing needs of patients and services, in a prevention-oriented integrated NHS, said HEE.

Malcolm commented: 'With the Long Term Plan for the NHS setting a clear strategic direction for the service and a strong commitment to develop the workforce, the timing couldn't be more appropriate to work with partners across the system to 'futureproof' the dental workforce for generations to come.

'I look forward to working closely with colleagues, dental organisations, other stakeholders and patients so that, together, we can produce models and pathways to enable oral health to take its rightful place in the holistic healthcare improvement.'

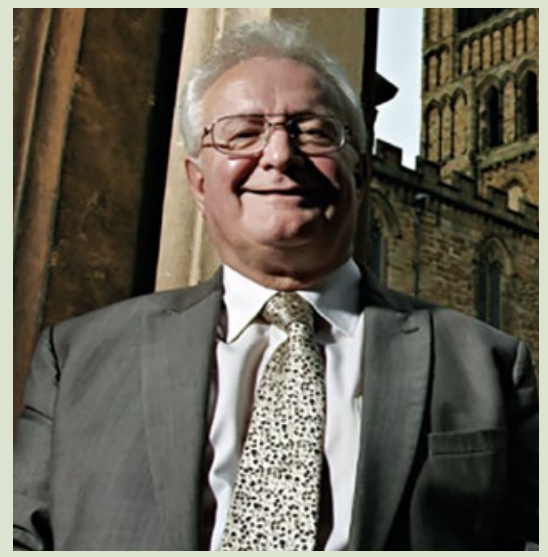

\section{There is mo such thing as a sugar rush!}

Research has found that sweet treats have no impact on mood and that the concept of a sugar rush may be a myth. The research was carried out by the Humboldt University of Berlin, with help from academics at the universities of Warwick and Lancaster and published in the journal Neuroscience and Biobehavioral Reviews.

A review of 31 research papers led by Dr Konstantinos Mantantzis revealed that eating carbohydrates has no effect on mood. This is true regardless of how much sugar is consumed or the activities people perform afterwards.

They found munching on caramel, toffee or fudge leaves people feeling exhausted and less alert an hour later. 